International Journal of Engineering \& Technology, $7(2.7)(2018) 597-601$
International Journal of Engineering \& Technology
WPC
Website: www.sciencepubco.com/index.php/IJET
Research Paper

\title{
A compact disc loaded curved elliptical shaped ultra-wideband MIMO antenna
}

\author{
EVV Satyanarayana*, Vivek Kumar, D. Mallikarjun Reddy, T. Siva Paravathi, J. Chandrasekhar Rao \\ Department of ECE, Koneru Lakshmaiah Education Foundation, Vaddeswaram, Guntur, Andhra Pradesh, India-522502. \\ *Corresponding author E-mail: satya.e1996@gmail.com
}

\begin{abstract}
The ultra wide band (UWB) Multiple-Input- Multiple-Output (MIMO) antenna with coplanar waveguide (CPW) having size of 18 x 23 x $0.8 \mathrm{~mm}^{3}$ is designed for ultra-wideband (UWB) applications. The designed MIMO antenna contains two symmetrical circular disc loaded curved elliptical monopoles on top of the substrate and common ground plane with Y slot and extended T-shaped stub on bottom of substrate. The T- shape stub is placed on the ground plane to have the better antenna impedance matching and to enhance the isolation between the two antenna ports. To further improve the isolation in between the ports 1 and 2, and also on the ground plane a Y-shaped slot is fixed. Good impedance matching $\left(\left|\mathrm{S}_{11}\right|<-10 \mathrm{~dB}\right)$ in the range from $2.8 \mathrm{GHz}$ to $12 \mathrm{GHz}$ is provided by the proposed antenna, and an enhanced isolation of $-27 \mathrm{~dB}$, low ECC of below 0.002 , an acceptable gain of about $7 \mathrm{dBi}$ and an efficiency of above $90 \%$. The obtained result proves that the designed antenna is more appropriate for the portable devices.
\end{abstract}

Keywords: Envelop Correlation Coefficient (ECC); Impedance Matching; Multiple Input Multiple Output (MIMO); Mutual Coupling; Ultra- Wideband.

\section{Introduction}

Ultra-wideband (UWB) technology is the most useful technology for short distance communications in Wireless Body Area Networks (WBAN) and Wireless Personal Area Networks (WPAN) due to its attractive features like less cost, very high security, high information rate transmission, impulse like channel response and low power consumption. It transmits data at lower power levels by using the wider bandwidths. Ultra wideband technology gained more attention of researchers since the Federal Communications Commission (FCC) approved $3.1 \mathrm{GHz}$ to $10.6 \mathrm{GHz}$ unlicensed frequency range with emission power level of $<-41.3 \mathrm{dBm} / \mathrm{MHz}$ for UWB technology for commercial applications in 2002 [1]. However, ultra-wideband technology suffers from the multipath fading problem in indoor environments which limits distance of communication. MIMO technology provides the feasible solution for multipath fading problem by exploiting multipath to improve the range of communication without the need of extra power and spectrum. However, placing several antennas with compact size and less mutual coupling between them in a space limited portable devices is always a tedious task for antenna designers [2, 3]. Several decoupling structures for UWB MIMO antennas were proposed in the literature to provide low mutual coupling between antenna elements for wireless portal devices [4, 14]. The decoupling structures includes tree like structures [4], a cross shaped slot [5], protruded ground stubs [6,8], a wide band neutralization [9], a metal reflector between the antenna elements [10], a Tshaped ground stub [11], couple of defected ground structures [12, 13], and T-shaped stub with Y slot structure [14]. A compact UWB MIMO antenna of size $18 \times 23 \times 0.8 \mathrm{~mm}^{3}$ for portable devices applications is proposed in this paper. Two symmetrical disc loaded curved elliptical monopoles which are fed by coplanar waveguide feed are used as radiating elements of proposed UWB MIMO antenna. The common ground plane consists of protruded ground with $\mathrm{Y}$ shaped slot and an extended T-shaped stub. The proposed antenna has a good impedance matching in the between from 2.8 to $12 \mathrm{GHz}$ frequency range. $\left(\left|\mathrm{S}_{11}\right|<-10 \mathrm{~dB}\right)$, low mutual coupling $\left(\left|\mathrm{S}_{21}\right|<-27 \mathrm{~dB}\right)$, stable peak gain and radiation efficiency covering the whole Ultra-wideband range[16-27]. The following sections describe the antenna design process, effect of T-shaped stub and Y slot.

\section{Antenna Design}

The ultra wide band (UWB) Multiple-Input- Multiple-Output (MIMO) antenna with coplanar waveguide (CPW) feed with the dimensions of $\mathrm{L} \times \mathrm{W} \times \mathrm{h}=18 \mathrm{~mm} \times 23 \mathrm{~mm} \times 0.8 \mathrm{~mm}$ is depicted in the Figure 1. The MIMO antenna is etched on the F4B-2 substrate material having $0.8 \mathrm{~mm}$ thickness, the dielectric constant $\left(\varepsilon_{\mathrm{r}}\right)$ of 2.65 , and the loss tangent 0.02 . The proposed antenna contains two symmetrical disc loaded curved elliptical monopoles radiating antennas which are fed by coplanar waveguide by $50-\Omega$ on top of the substrate as depicted in the Figure 1. A protruded ground with Y shaped slot and a T- shape stub is employed on the other side of substrate. To enhance the antenna impedance matching and to improve isolation $\left(\mathrm{S}_{21}\right)$ in between the antenna ports, the T- shape stub is deployed on to the common ground plane. To even more increase the isolation a Y-shape slot is used on the ground plane. The Table 1 shows the improved dimensions of the proposed antenna. 
Table 1: Dimensions of the proposed antenna (in $\mathrm{mm}$ )

\begin{tabular}{|c|c|c|c|c|}
\hline $\mathrm{L}$ & $\mathrm{W}$ & $\mathrm{L} 1$ & $\mathrm{~L} 2$ & $\mathrm{~A}$ \\
\hline $18 \mathrm{~mm}$ & $23 \mathrm{~mm}$ & $9.2 \mathrm{~mm}$ & $6.5 \mathrm{~mm}$ & $0.4 \mathrm{~mm}$ \\
\hline $\mathrm{L} 3$ & $\mathrm{~L} 4$ & $\mathrm{~L} 5$ & $\mathrm{~L} 6$ & $\mathrm{D}$ \\
\hline $4.9 \mathrm{~mm}$ & $2.6 \mathrm{~mm}$ & $1.2 \mathrm{~mm}$ & $3 \mathrm{~mm}$ & $4 \mathrm{~mm}$ \\
\hline $\mathrm{L} 7$ & $\mathrm{~L} 8$ & $\mathrm{~W} 1$ & $\mathrm{~W} 2$ & $\mathrm{~W} 3$ \\
\hline $1.6 \mathrm{~mm}$ & $6.9 \mathrm{~mm}$ & $2.4 \mathrm{~mm}$ & $10.3 \mathrm{~mm}$ & $7 \mathrm{~mm}$ \\
\hline
\end{tabular}

\section{Results And Discussions}

The measures of the designed antenna are optimized and antenna is simulated using the Ansoft's HFSS v.13 software. The parameters of antenna like impedance matching, surface current distributions, mutual coupling, peak gain, radiation patterns, and radiation efficiency of the designed antenna are discussed in the sections. The Figure 2 and 3 illustrates the S-parameters at different stages of the proposed antenna. It can be viewed from the Figures 2 and 3 , that without $\mathrm{T}$ shaped stub and $\mathrm{Y}$ slot on ground plane the ultra wideband MIMO antenna has lower resonant frequency at 6.2 $\mathrm{GHz}$ which is very larger than $3.1 \mathrm{GHz}$ and mutual coupling of about $-12 \mathrm{~dB}$. With $\mathrm{T}$ stub and without $\mathrm{Y}$ slot on ground plane the antenna is resonating at $3 \mathrm{GHz}$ which is below $3.1 \mathrm{GHz}$ and mutual coupling of lower than $-25 \mathrm{~dB}$ in between the elements of the antenna as observed from Figure 2 and 3. With the use of $\mathrm{T}$ shaped stub and Y slot (proposed antenna) very good impedance matching in the frequency range from $2.8 \mathrm{GHz}$ to $12 \mathrm{GHz}\left(\mathrm{S}_{11}<-10 \mathrm{~dB}\right)$, and a good isolation of less than $-27 \mathrm{~dB}$ is obtained as seen from the Figure 2 and 3 . The $\mathrm{T}$ shaped stub acts as a reflector which diverts the currents on the antenna. Hence, the T shaped stub improves impedance matching over entire ultra wideband and also improves the isolation in between the ports. The isolation is further enhanced by inclusion of Y slot on the ground plane.

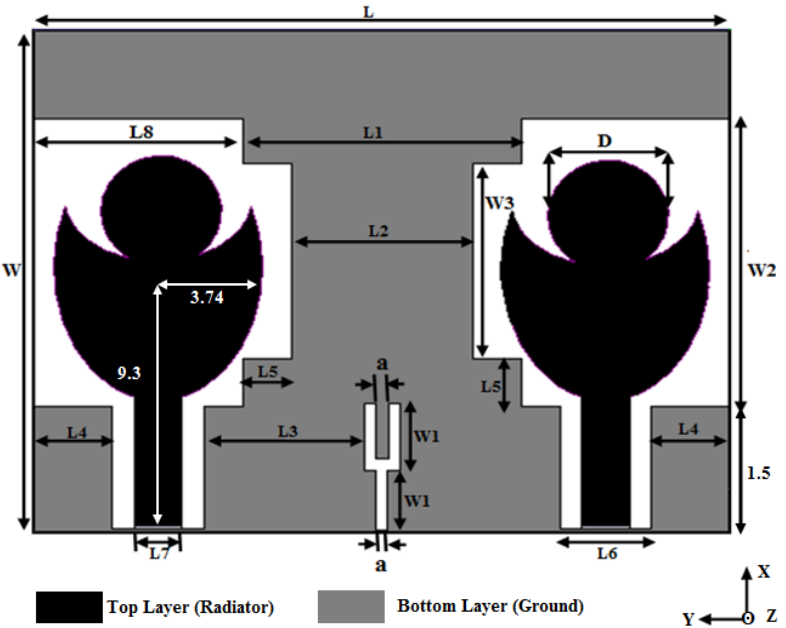

Fig. 1: Geometry of the proposed UWB MIMO antenna

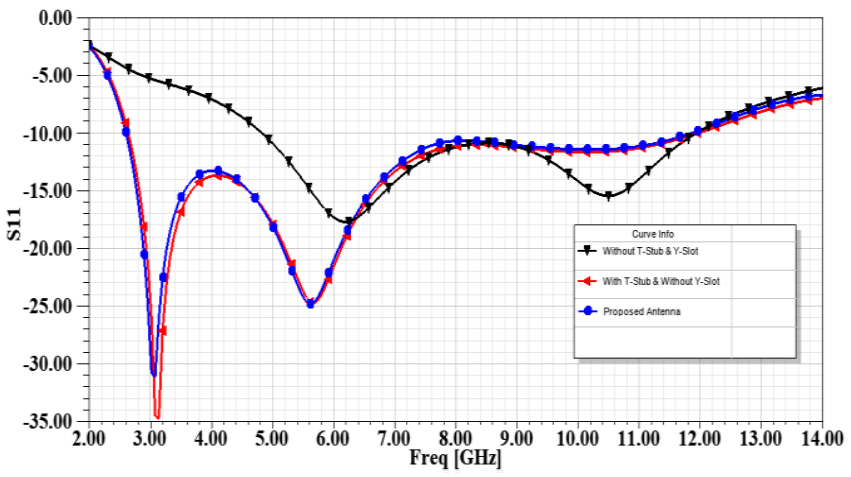

Fig. 2: $\mathrm{S}_{11}$ parameter of proposed antenna

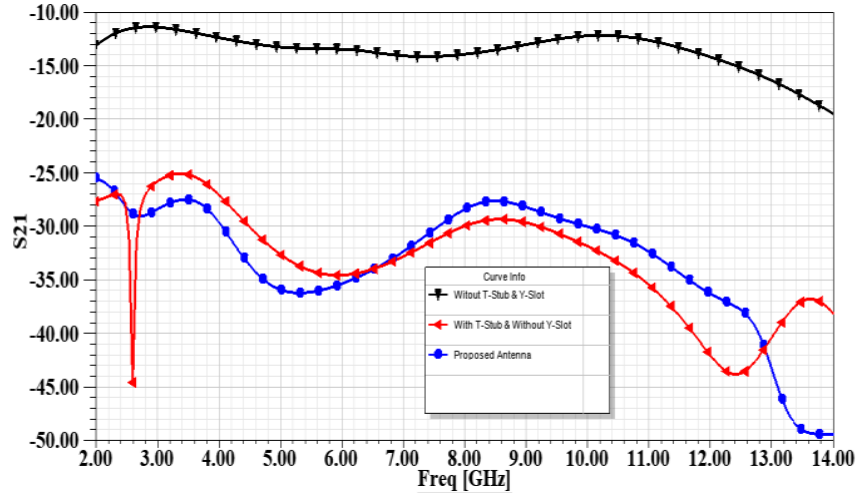

Fig. 3: $S_{21}$ parameter of proposed antenna

The effect of T-shape stub and Y-shape slot on the performance of UWB MIMO antenna is clearly explained by surface current distributions at $10.6 \mathrm{GHz}$ which is shown in the Figure 4 (a) - (c). It can be viewed from the Figures 4 (b) and 4 (c) that $T$ shaped stub and Y slot efficiently blocking the surface currents entering from the ports 1 to 2 .

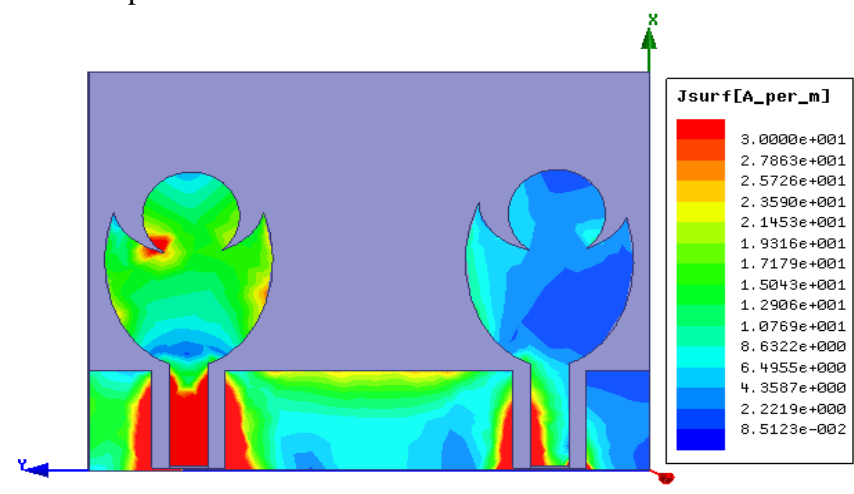

Fig. 4 (a): Without T stub and Y slot on ground.

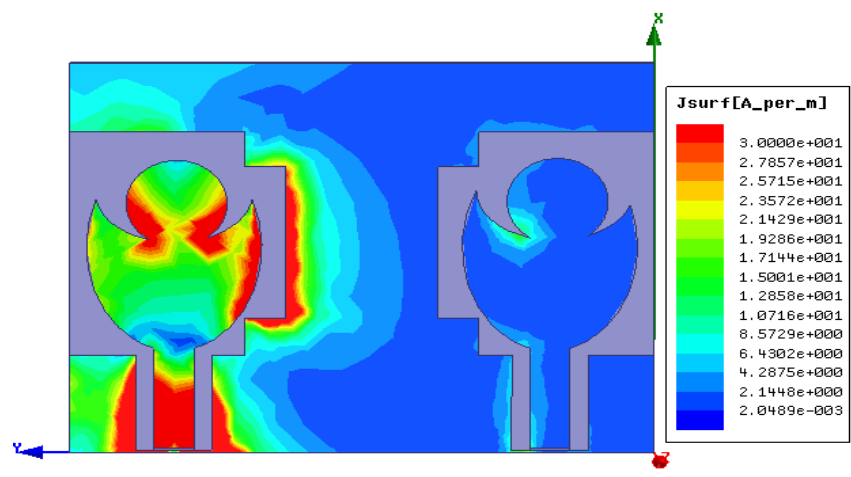

Fig. 4 (b): With T stub and without Y slot on ground.

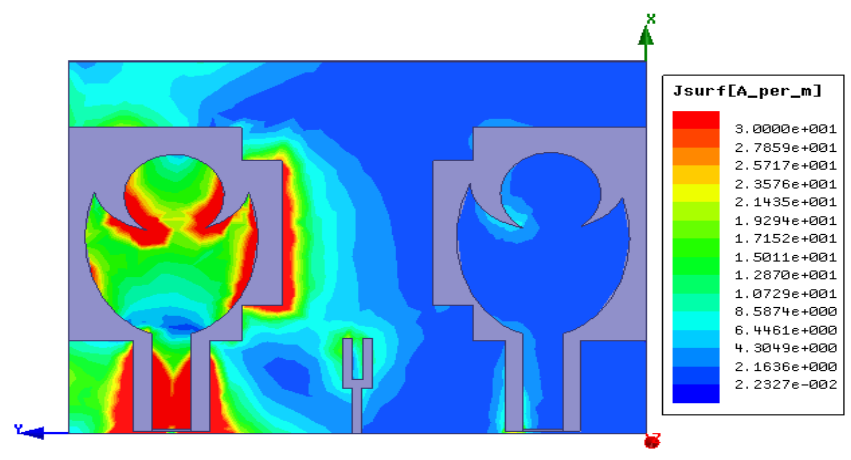

Fig. 4 (c): Proposed antenna.

Fig. 4: Effect of T stub and Y slot on UWB MIMO antenna.

The diversified performance of the designed antenna has been analyzed by using surface current distributions, 3-D radiation patterns, and envelope correlation coefficient (ECC). Figure 5 (a) 5 (c) describes the surface current distributions when the port- 1 is 
excited at frequencies of 3.1, 5.6, and $10.6 \mathrm{GHz}$ respectively. It is clearly evident from the Figure 5 that huge current is radiated by the port 1 and very negligible amount of current is leaked into port 2. Similarly, from Figure 6 (a) - 6 (c), it is seen that most of the current is radiated from port 2 and considerably less current is entering into port 1 . Hence, the proposed antenna giving good diversity performance in entire UWB ranges.

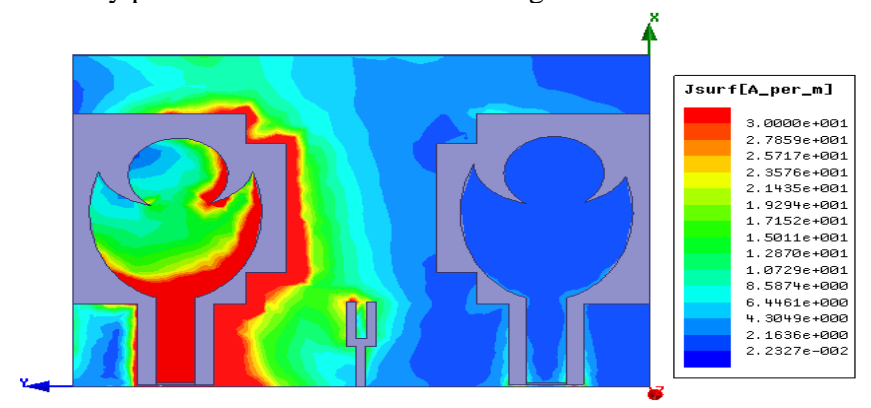

Fig. 5 (a): Current distribution at $3.1 \mathrm{GHz}$

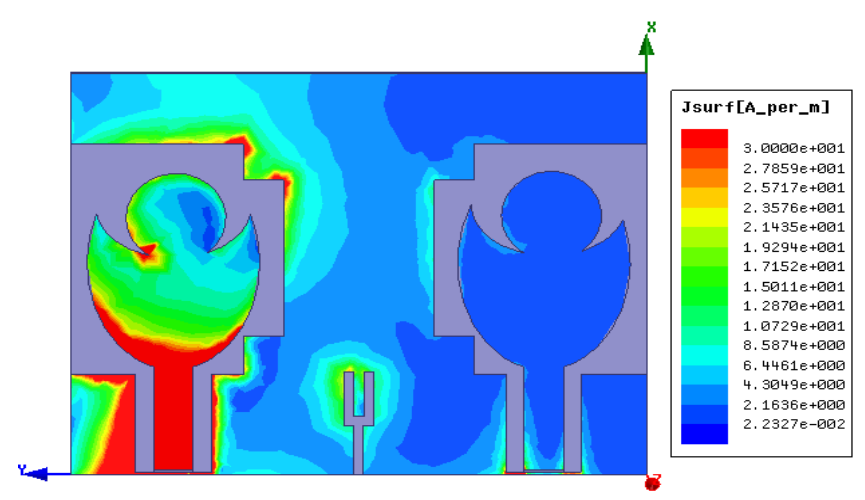

Fig. 5 (b): Current distribution at $5.6 \mathrm{GHz}$.

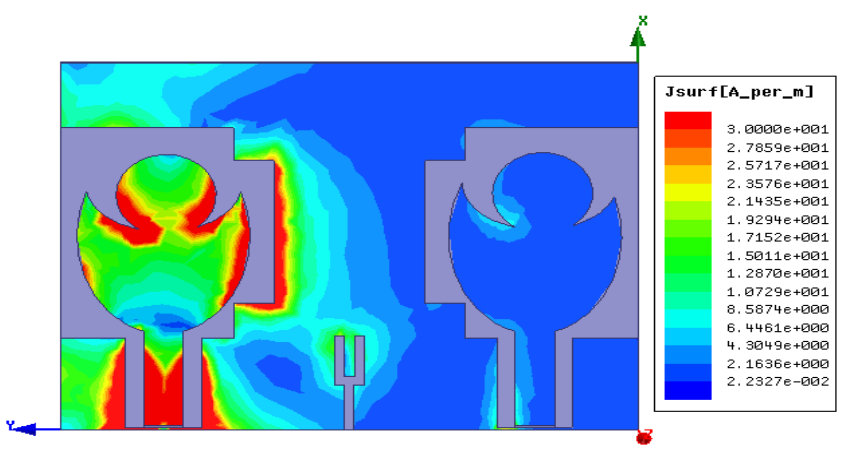

Fig. 5(c): Current distribution at $10.6 \mathrm{GHz}$.

Fig. 5: Current distributions when the port 1 is excited.

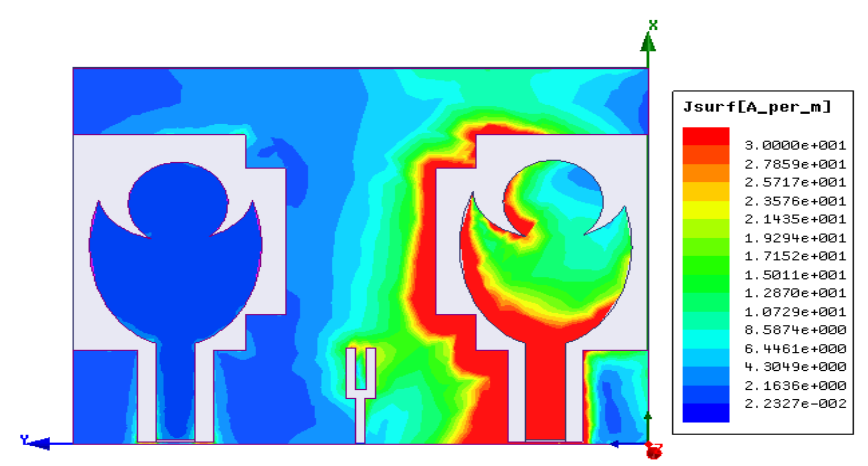

Fig. 6 (a): Current distribution at $3.1 \mathrm{GHz}$.

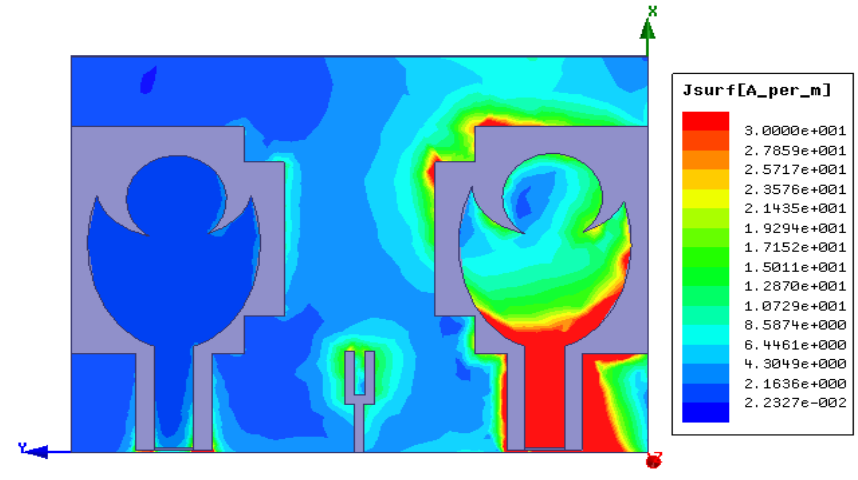

Fig. 6 (b): Current distribution at $5.6 \mathrm{GHz}$

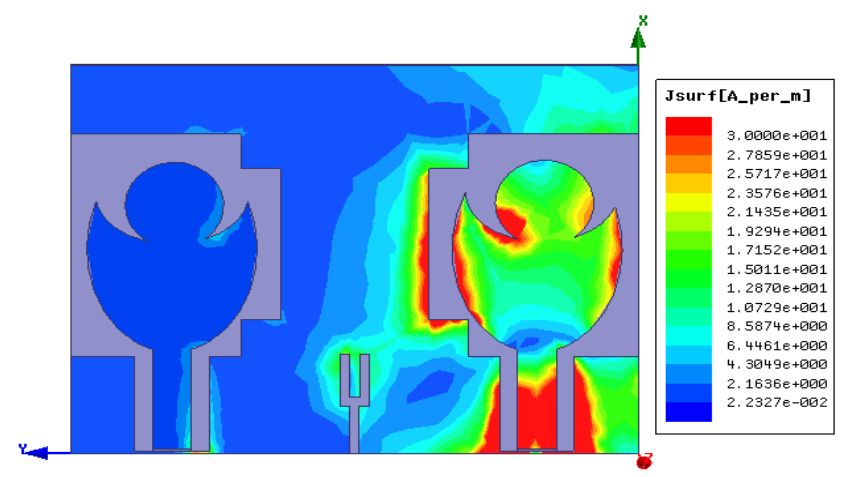

Fig. 6 (c): Current distribution at $10.6 \mathrm{GHz}$.

Fig. 6: Current distribution when port 1 excited

The 3-D polar plots shown in Figure 7 and 8 illustrates the proposed antenna pattern diversity when the port- 1 is excited and the port- 2 is ended with load of $50 \Omega$ and vice-versa at $3.1 \mathrm{GHz}, 5.6$ $\mathrm{GHz}$, and $10.6 \mathrm{GHz}$, respectively. It is observed from the Figures 7 and 8 that the patterns are diverted by some angles, hence good pattern diversity is achieved.
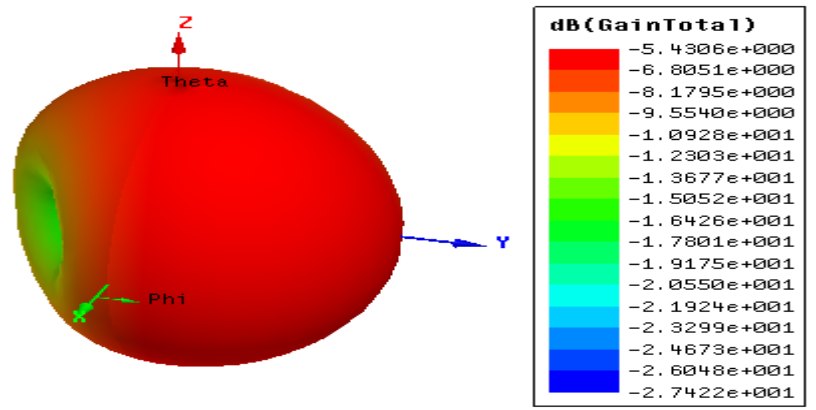

Fig. 7 (a): 3-D polar plot at $3.1 \mathrm{GHz}$.

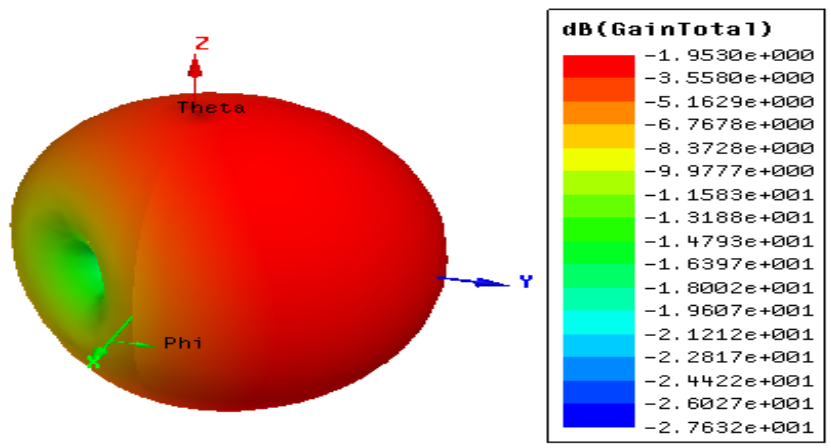

Fig. 7 (b): 3-D polar plot at $5.6 \mathrm{GHz}$. 


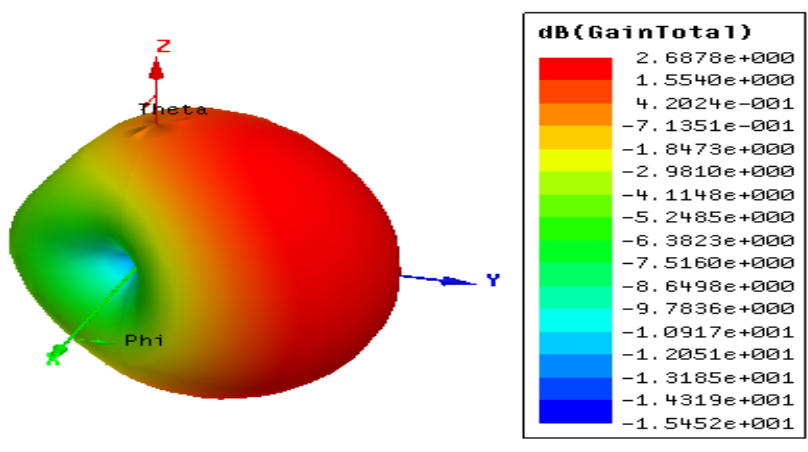

Fig. 7 (c): 3-D polar plot at $10.6 \mathrm{GHz}$.

Fig. 7: 3-D polar plots when port 1 excited.
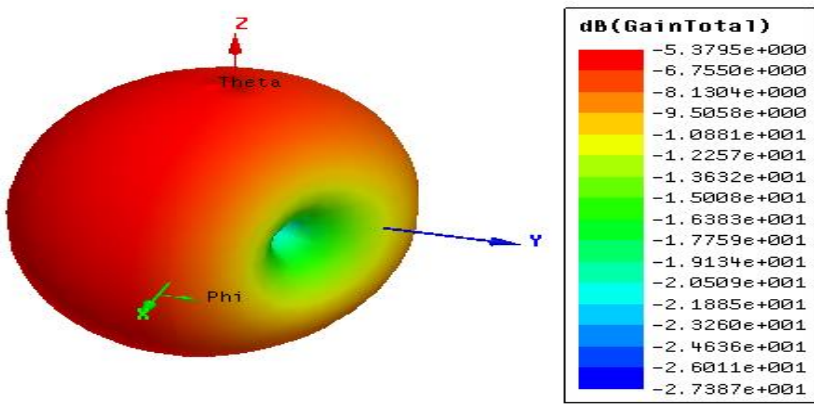

Fig. 8 (a): 3-D polar plot at $3.1 \mathrm{GHz}$.
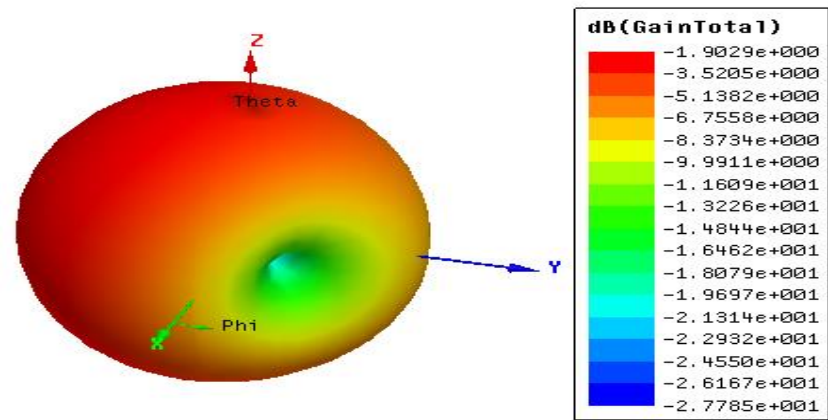

Fig. 8 (b): 3-D polar plot at $5.6 \mathrm{GHz}$.
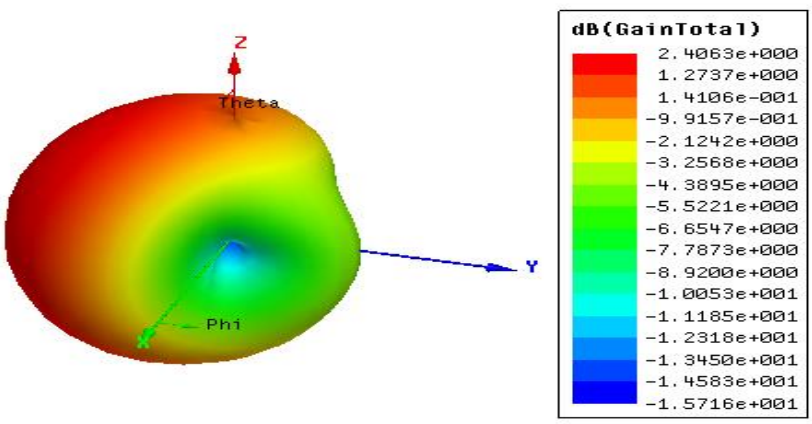

Fig. 8 (c): 3-D polar plot at $10.6 \mathrm{GHz}$

Fig. 5: 3-D polar plots when the port 2 is excited.

ECC measures the similarity between the antenna radiations. For the proposed antenna the simulated ECC is computed using the Equation (1) for 2-port network proposed by Blanch in [15]. Figure 9 shows the proposed antenna ECC which is low in the designed UWB range. Figure 10 show that the maximum peak gain of the proposed antenna is ranging between $0.4 \mathrm{dBi}$ to $7 \mathrm{dBi}$ in the UWB band. Figure 11 show that the proposed antenna has the maximum efficiency of about $96 \%$ over the UWB range.

$E C C=\frac{\left|S_{11}^{*} S_{12}+S_{21}^{*} S_{22}\right|^{2}}{\left(1-\left(\left|S_{11}\right|^{2}+\left|S_{21}\right|^{2}\right)\right)\left(1-\left(\left|S_{22}\right|^{2}+\left|S_{12}\right|^{2}\right)\right)}$,

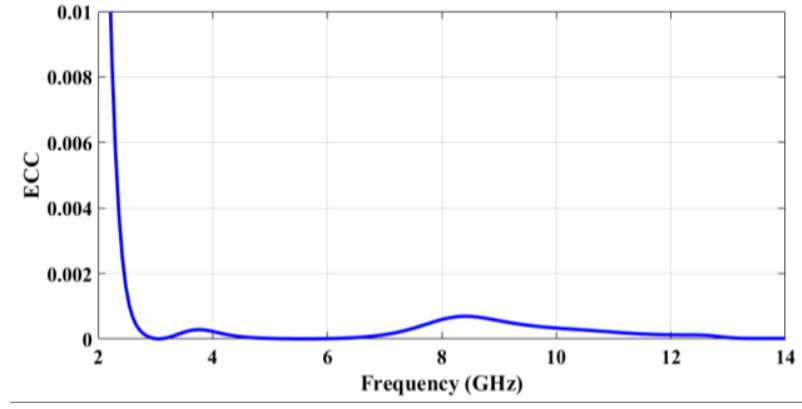

Fig. 9: ECC of the simulated antenna

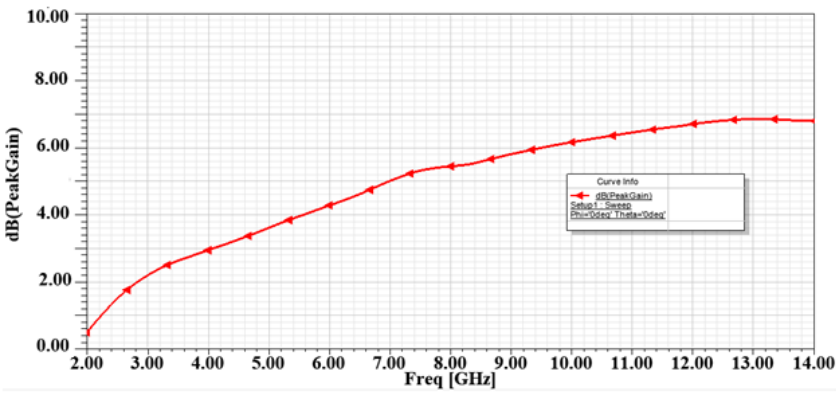

Fig. 10: Peak gain of the simulated antenna.

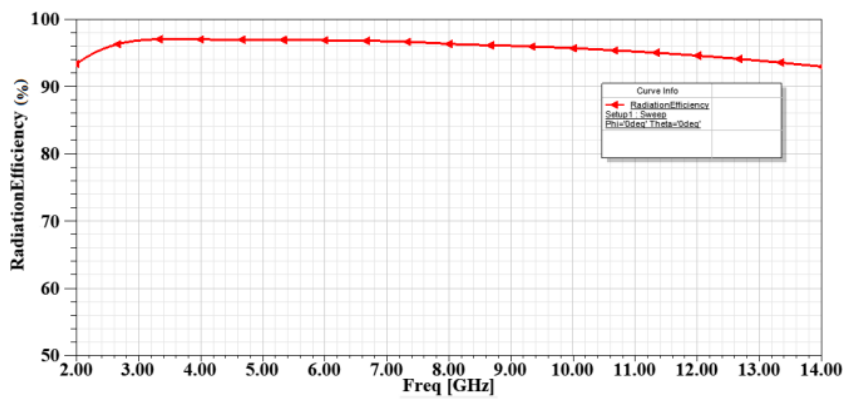

Fig. 11: Radiation efficiency of the simulated antenna.

\section{Conclusion}

A compact multi input multi output ultra-wideband antenna for wireless portable device communications is proposed in this paper. To symmetrical disc loaded curved elliptical shaped monopoles and common ground with a Y slot and T shaped stub constitute the ultra wideband MIMO antenna. The antenna is fed by coplanar waveguide feed. The proposed antenna is giving best impedance matching $\left(\left|S_{11}\right|<-10 \mathrm{~dB}\right)$ from $2.8 \mathrm{GHz}$ to $12 \mathrm{GHz}$, an improved isolation of $-27 \mathrm{~dB}$, a very low ECC of below 0.002 , reasonable peak gain of $7 \mathrm{dBi}$ and good efficiency of above $90 \%$. The obtained results shows that the designed MIMO UWB antenna is well fitted for portable device communications.

\section{Acknowledgement}

I would like to sincerely thank J. Chandrasekhar Rao for his tremendous support during the completion of this project. I would like to express my sincere thanks to Koneru Lakshmaiah education foundation for the support and help they provided during the completion of the project.

\section{References}

[1] Federal Communications Commission (FCC). Revision of Part 15 of the Commission's Rules Regarding Ultra- Wideband Transmission Systems First Rep. and Order, ET Docket, FCC; 2002 Apr. p. 98-153. 
[2] Zheng L, Tse NC., "Diversity and multiplexing: A fundamental trade-off in multiple-antenna channels," IEEE Trans. Inf. Theory 2003;49(5):1073-6.

[3] Migliore MD., "An investigation on UWB-MIMO communication systems based on an experimental channel characterization," IEEE Transactions on Antennas and Propagation. 2008; 56(9):3081-3.

[4] Zhang S, Ying Z, Xiong J, He S, "Ultra-wideband MIMO/ diversity antennas with a tree-like structure to enhance wideband isolation," IEEE Antennas and Wireless Propagation Letters. 2009; 8:1279-82.

[5] Zhang Y, Niu B., "Compact Ultra-Wideband (UWB) slot antenna with wideband and high isolation for MIMO applications," Progress in Electromagnetics Research C. 2014; 54:9-16.

[6] Liu L, Cheung SW, Yuk TI., "Compact MIMO antenna for portable devices in UWB applications," IEEE Trans Antennas and Propag., 2013;61(8):4257-4.

[7] J. Chandrasekhar Rao and N. Venkateswara Rao, "CPW-Fed Compact Ultra-Wideband MIMO Antenna for Portable Devices", Indian Journal of Science and Technology,09746846, Vol 9, Issue 17, May 2016, pp. 1-9.

[8] J. Chandrasekhar Rao, N. Venkateswara Rao, B.T. P. Madhav, V. Vasavi, K. Vyshnavi and G. S. K Yadav, "Compact UWB MIMO Slot Antenna with Defected Ground Structure," ARPN Journal of Engineering and Applied Sciences, vol. 11, no. 17, pp. 10487-10495, September 2016.

[9] Shuai Zhang; Gert Frølund Pedersen, "Mutual Coupling Reduction for UWB MIMO Antennas with a Wideband Neutralization Line," IEEE Antennas Wireless Propag. Lett, vol. PP, pp.1 $-1,2015$.

[10] Roshna, T.K.; Deepak, U.; Sajitha, V.R., et al., "A Compact UWB MIMO Antenna with Reflector to Enhance Isolation," IEEE Trans. Antennas Propag, vol. 63, pp. 1873 - 1877, 2015.

[11] Li Liu, S. W. Cheung, and T. I. Yuk, "Compact MIMO Antenna for Portable UWB Applications with Band-Notched Characteristic," IEEE Trans. Antennas Propag, vol. 63, pp. 1917 1924, 2015.

[12] Luo, C.; Hong, J.; Zhong, L., "Isolation Enhancement of a Very Compact UWB-MIMO Slot Antenna with Two Defected Ground Structures," IEEE Antennas Wireless Propag. Lett, vol. PP, pp. 1 - 1, 2015.

[13] Chandrasekhar Rao Jetti, Venkateswara Rao Nandanavanam, "Trident-Shape Strip Loaded Dual Band-Notched UWB MIMO Antenna for Portable Device Applications", AEU-International Journal of Electronics and Communications (Elsevier B.V.), ISSN: 1434-8411, vol. 83, 11-21, 2018.

[14] Jun Tao and Quanyuan Feng., "Compact ultra- wideband MIMO antenna with half-slot structure," vol. 16, pp. 792-795, 2017.

[15] Blanch, S., Romen, J., and Corbella, I., "Exact representation of antenna system diversity performance from input parameter description," Electronics Letters, Vol. 39, 705-707, 2003.

[16] Madhav, B.T.P., Pisipati, V.G.K.M., Khan, H. And Ujwala, D. 2014. Fractal Shaped Sierpinski On Ebg Structured Ground Plane. Leonardo Electronic Journal Of Practices And Technologies, 13(25), Pp. 26-35.

[17] Madhav, B.T.P., Mohan Reddy, S., Ravindranath Chowdary, J., Vinod Babu, V., Satya Parthiva, S. And Kalyana Saravana, S., 2013. Analysis Of Dual Feed Asymmetric Antenna. International Journal Of Applied Engineering Research, 8(4), Pp. 461-467.

[18] Madhav, B.T.P., Ujwala, D., Khan, H., Tejaswani, A.L., Guntupalli, S. And Bala, A., 2013. Substrate Permittivity Effects On The Performance Of Slotted Aperture Stacked Patch Antenna. International Journal Of Applied Engineering Research, 8(8), Pp. 909-916.

[19] Sadasivarao, B. And Madhav, B.T.P., 2014. Analysis Of Hybrid Slot Antenna Based On Substrate Permittivity. Arpn Journal Of Engineering And Applied Sciences, 9(6), Pp. 885-890.

[20] Lakshmikanth, P., Takeshore, K. And Madhav, B.T.P., 2015 Printed Log-Periodic Dipole Antenna With Notched Filter At 2.45 Ghz Frequency For Wireless Communication Applications. Journal Of Engineering And Applied Sciences, 10(3), Pp 40-44.

[21] Madhav, B.T.P., Krishnam Naidu Yedla, G.S., Kumar, K.V.V., Rahul, R. And Srikanth, V., 2014. Fractal Aperture Ebg Ground Structured Dual Band Planar Slot Antenna. International Journal Of Applied Engineering Research, 9(5), Pp. 515-524.
[22] Madhav, B.T.P., Kotamraju, S.K., Manikanta, P., Narendra, K., Kishore, M.R. And Kiran, G., 2014. Tapered Step Cpw-Fed Antenna For Wideband Applications. Arpn Journal Of Engineering And Applied Sciences, 9(10), Pp. 1967-1973.

[23] Madhav, B.T.P., Mohan Reddy, S.S., Sanjay, B. And Ujwala, D., 2013. Trident Shaped Ultra Wideband Antenna Analysis Based On Substrate Permittivity. International Journal Of Applied Engineering Research, 8(12), Pp. 1355-1361.

[24] Madhav, B.T.P., Sanikommu, M., Pranoop, M.S., Bose, K.S.N.M.C. And Kumar, B.S., 2015. Cpw Fed Antenna For Wideband Applications Based On Tapered Step Ground And Ebg Structure. Indian Journal Of Science And Technology, 8 Pp. 119-127.

[25] Madhav, B.T.P., Kumar, K.V.V. And Manjusha, A.V., 2014. Analysis Of Cpw Fed Step Serrated Ultra Wide Band Antenna On Rogers Rt/Duroid Substrates. International Journal Of Applied Engineering Research, 9(1), Pp. 53-58.

[26] Mohan Reddy, S.S., Mallikarjuna Rao, P. And Madhav, B.T.P., 2015. Asymmetric Defected Ground Structured Monopole Antenna For Wideband Communication Systems. International Journal On Communications Antenna And Propagation, 5(5), Pp. 256-262.

[27] Madhav, B.T.P., Manikanta Prasanth, A., Prasanth, S., Krishna, B.M.S., Manikantha, D. And Nagasai, U.S., 2015. Analysis Of Defected Ground Structure Notched Monopole Antenna. Arpn Journal Of Engineering And Applied Sciences, 10(2), Pp. 747 752 . 